\title{
A Study on Physical Aging of Semicrystalline Polyethylene Terephthalate below the Glass Transition Point
}

\author{
M. Farhoodi ${ }^{1}$, S. M. Mousavi ${ }^{2}$, R. Sotudeh-Gharebagh ${ }^{3}$, Z. Emam-Djomeh ${ }^{*}{ }^{4}$, A. Oromiehie ${ }^{5}$, H. Mansour ${ }^{6}$ \\ 1, 2, 4 Department of Food Science and Technology, Faculty of Agricultural Engineering, \\ University of Tehran, P.O.Box 31587-77871, Karaj, Iran, \\ *emamj@ut.ac.ir \\ ${ }^{3}$ School of Chemical Engineering, College of Engineering, \\ University of Tehran, P.O. Box 11155/4563, Tehran, Iran \\ 5 Iran Polymer and Petrochemical Institute, P.O. Box: 14965/159, Tehran, Iran \\ ${ }^{6}$ Iranian Offshore Oil Company, P. O. Box 79781-79717, Lavan, Iran
}

\begin{abstract}
Physical aging of semicrystalline polyethylene terephthalate was studied using differential scanning calorimetry (DSC). PET samples with crystallinity content of 0.28 were aged at two different temperatures, 25 and $45^{\circ} \mathrm{C}$. The samples were stored for several days and periodically tested using DSC method. The glass transition temperature for the samples aged at $25^{\circ} \mathrm{C}$ was about $73-74^{\circ} \mathrm{C}$, and the position and intensity of endothermic peaks were approximately constant. Higher glass transition of the samples aged at $45^{\circ} \mathrm{C}, 73-86^{\circ} \mathrm{C}$, was attributed to the enthalpy relaxation process of amorphous regions of semicrystalline PET. For the samples aged at $45^{\circ} \mathrm{C}$, the endothermic peaks shifted to higher temperatures with increasing aging time. The position of the endothermic peaks determined by the temperature of the maximum, Tmax, tended to increase with aging time for samples aged at $45^{\circ} \mathrm{C}$, and the intensity of the peaks continuously increased with time; however, the results showed that the aging of PET samples at $45^{\circ} \mathrm{C}$ even after 120 days continued the enthalpic relaxation of semicrystalline PET and that the process could be studied by DSC method. The results also showed that the aging process could affect the final degree of crystallinity of C-PET samples and the samples stored at $45^{\circ} \mathrm{C}$ showed higher degree of crystallinity than the samples aged at $25^{\circ} \mathrm{C}$.
\end{abstract}

Keywords: Enthalpy Relaxation, Glass Transition, Endothermic Peak, Polyethylene Terephthalate, Crystallization.

\section{Introduction}

PET is a copolymer of ethylene glycol with either terephthalic acid or dimethyl terephthalate; it is commonly used as packaging material because of its beneficial thermal and mechanical properties, chemical resistance, great ability to form fibers, low permeability in $\mathrm{O}_{2}$ and $\mathrm{CO}_{2}$ and melt processability. The properties of PET highly depend on its chemical structure but also on its crystallinity, orientation and molecular weight. The mobility of polymer chains during storage time needed to reach a stable equilibrium state can change the mechanical, microstructural and thermodynamic properties of polymer. Physical aging affects the physical properties of all polymers to various extents. In semicrystalline polymers, physical aging occurs in the amorphous regions and adjusts the thermomechanical response of polymers. The presence of crystals in a semicrystalline polymer is known to constrain the amorphous phase and to influence the glass transition region [1]. The segmental mobility of the amorphous phase near the crystals is reduced, whereas at large distances from the crystals, the amorphous phase has the same properties as in the bulk amorphous polymer.

According to Struik [2], the glass transition of semicrystalline polymers is broader than the amorphous one and extends toward the hightemperature side. $\mathrm{He}$ found that most of semicrystalline polymers show strong aging effects at temperatures below as well as above the conventional glass transition temperature of the material [3]. Lu et al. (2000) showed that the storage of amorphous PET below the glass transition increases the rates of subsequent cold crystallization on heating above the glass transition temperature, $T_{g}$, and the increase in crystallization rate depends on the extent of physical aging which 
has developed [4]. Ellis et al. (2006) investigated the process of physical aging in a blend of deuterated and hydrogenated polyethylene terephthalate and they reported the development of an endothermic peak on the glass transition using DSC [5]. Doulache et al. (2010) studied the effect of aging in partially crystallized polyethylene terephthalate $(14 \%)$ by differential scanning calorimetry (DSC) and found that the influence of the thermal history of the polymer is important for a slow cooling rate and a long annealing time [6]. There are also some reports on the effect of physical aging on the crystallization process of semicrystalline polymers [7, 8]. Zhou et al. (2008) studied the primary degree effect of crystallinity $\left(X_{c}\right)$ of polyethylene terephthalate on the crystallinity of polymer chains during aging. They observed that in the c-PET samples with $X_{c}>0.2$, the rate of crystallinity increases more slowly than in the samples with $X_{c}=0.1-0.2$ during aging [9]. In this study, the effect of physical aging on the glass transition point and crystallization process of semicrystalline polyethylene terephthalate at two aging temperatures, 25 and $45^{\circ} \mathrm{C}$, was investigated.

\section{Materials and methods}

Semicrystalline PET samples (BG-821, bottlegrade, Shahid Tondguyan Petrochemical Co., Iran) with high degree of crystallinity $\left(X_{c}=0.28\right)$ were used in this study. The glass transition temperature of the PET material was $73.26^{\circ} \mathrm{C}$ as shown in Figure 1. The samples were analyzed with differential scanning calorimetry (DSC-2010 model, USA). The samples were subjected to physical aging at aging temperatures of 25 and $45^{\circ} \mathrm{C}$, for periods between 1 and 120 days. The melting behavior of aged samples was determined using heating and cooling tests between 25 to $270{ }^{\circ} \mathrm{C}$ at a rate of $\pm 10^{\circ} \mathrm{C} / \mathrm{min}$. The degree of crystallinity $\left(X_{c}\right)$ of $\mathrm{c}$-PET samples were calculated using Equation (1):

$$
\mathrm{X}_{\mathrm{C}}=\left(\frac{\Delta \mathrm{H}_{\mathrm{m}}}{\Delta \mathrm{H}_{\mathrm{m} 0}}\right) \times 100
$$

Where $\Delta \mathrm{H}_{\mathrm{m} 0}$ is the melting enthalpy of $100 \%$ crystalline PET $\left(\Delta \mathrm{H}_{\mathrm{m} 0}=135.8 \mathrm{~J} / \mathrm{g}\right.$ [10] $)$ and $\Delta \mathrm{H}_{\mathrm{m}}$ is the melting enthalpy of the samples.

\section{Results and Discussion}

\subsection{Effect of aging on glass transition point}

The values of glass transition temperature $\left(T_{g}\right)$, maximum temperature of the endothermic peak $\left(T_{\max }\right)$, melting temperature $\left(T_{m}\right)$, crystallization temperature $\left(T_{c}\right)$, enthalpy of crystallization $\left(\Delta H_{C}\right)$, enthalpy of melting $\left(\Delta \mathrm{H}_{\mathrm{m}}\right)$, and degree of crystallinity $\left(X_{c}\right)$ of the samples aged at 25 and $45^{\circ} \mathrm{C}$ are listed in Table 1 and 2, respectively. For the samples aged at $25^{\circ} \mathrm{C}$, the $T_{g}$ points do not change significantly during the aging time while for the samples aged at $45^{\circ} \mathrm{C}$ the intensity of the $T_{g}$ peaks tends to increase with aging time and the endothermic peaks become sharper with aging time (Figure 1). Also, the position of the endothermic peaks, determined by the temperature of the maximum, $T_{\max }$, tends to increase with aging time (Figure 2).

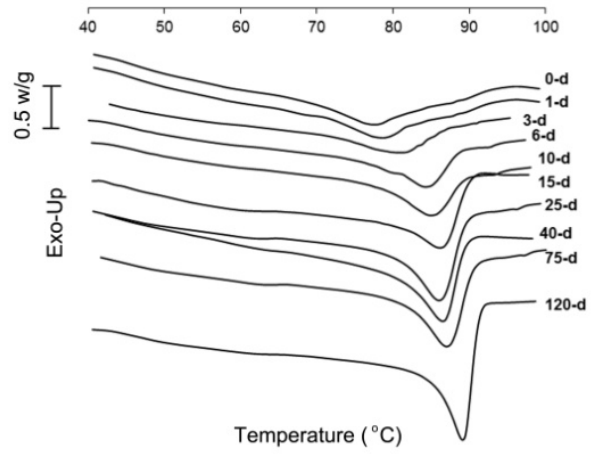

Figure 1. DSC curve of aged c-PET $\left(X_{C}=0.28\right)$ for an aging temperature of $45^{\circ} \mathrm{C}$, for periods of $0-120$ days.

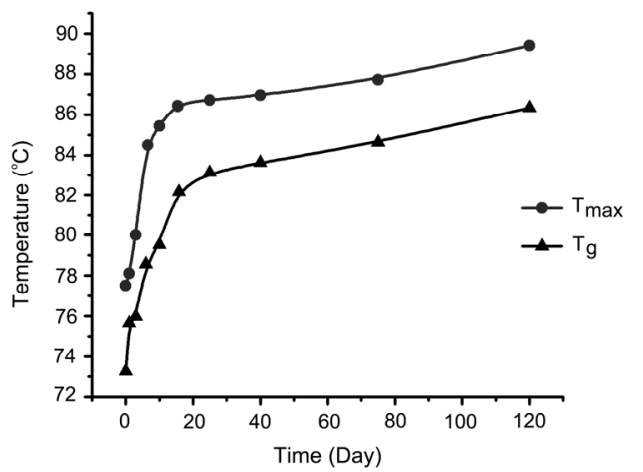

Figure 2. Dependence of the temperature of the maximum of the endothermic peak, $T_{\max }$, on aging time at $45^{\circ} \mathrm{C}$ for $\mathrm{C}-\mathrm{PET}\left(\mathrm{X}_{\mathrm{c}}=0.28\right)$. 


\begin{tabular}{cccccccc}
\hline Sample & $\mathrm{T}_{\mathrm{g}}$ & $\mathrm{T}_{\max }$ & $\mathrm{T}_{\mathrm{m}}\left({ }^{\circ} \mathrm{C}\right)$ & $\Delta \mathrm{H}_{\mathrm{m}}(\mathrm{J} / \mathrm{g})$ & $\mathrm{X}_{\mathrm{C}}(\%)$ & $\mathrm{T}_{\mathrm{c}}\left({ }^{\circ} \mathrm{C}\right)$ & $\Delta \mathrm{H}_{\mathrm{C}}(\mathrm{J} / \mathrm{g})$ \\
\hline 0 & 73.26 & 77.50 & 248.11 & 38.27 & 28.18 & 159.58 & 23.02 \\
1 & 73.30 & 77.54 & 248.16 & 38.18 & 28.11 & 159.44 & 23.00 \\
3 & 73.29 & 77.53 & 248.32 & 38.29 & 28.20 & 159.60 & 23.26 \\
6 & 73.32 & 77.56 & 248.42 & 38.34 & 28.23 & 159.62 & 24.02 \\
10 & 73.35 & 77.59 & 248.54 & 38.38 & 28.26 & 159.98 & 24.18 \\
15 & 73.42 & 77.66 & 248.42 & 38.24 & 28.16 & 160.88 & 24.22 \\
25 & 73.40 & 77.64 & 248.12 & 38.83 & 28.59 & 160.37 & 24.18 \\
40 & 73.48 & 77.72 & 247.98 & 39.46 & 29.06 & 160.97 & 24.90 \\
75 & 73.51 & 77.75 & 248.04 & 41.07 & 30.24 & 161.97 & 24.96 \\
120 & 73.63 & 77.87 & 247.52 & 41.62 & 30.65 & 164.21 & 26.48 \\
\hline
\end{tabular}

Table 1. The characteristic value of DSC analysis of c-PET samples aged at $25^{\circ} \mathrm{C}$.

\begin{tabular}{cccccccc}
\hline Sample & $\mathrm{T}_{\mathrm{g}}$ & $\mathrm{T}_{\max }$ & $\mathrm{T}_{\mathrm{m}}\left({ }^{\circ} \mathrm{C}\right)$ & $\Delta \mathrm{H}_{\mathrm{m}}(\mathrm{J} / \mathrm{g})$ & $\mathrm{X}_{\mathrm{C}}(\%)$ & $\mathrm{T}_{\mathrm{c}}\left({ }^{\circ} \mathrm{C}\right)$ & $\Delta \mathrm{H}_{\mathrm{C}}(\mathrm{J} / \mathrm{g})$ \\
\hline 0 & 73.26 & 77.50 & 248.11 & 38.27 & 28.18 & 159.58 & 23.02 \\
1 & 75.64 & 78.10 & 248.11 & 38.16 & 28.10 & 160.10 & 23.00 \\
3 & 75.97 & 80.00 & 248.04 & 38.27 & 28.18 & 160.15 & 23.26 \\
6 & 78.56 & 84.50 & 247.98 & 38.24 & 28.16 & 160.46 & 24.12 \\
10 & 79.51 & 85.44 & 248.07 & 39.65 & 29.20 & 160.64 & 25.29 \\
15 & 82.28 & 86.58 & 248.10 & 39.91 & 29.39 & 160.66 & 26.92 \\
25 & 83.13 & 86.72 & 248.01 & 40.08 & 29.51 & 161.93 & 27.28 \\
40 & 83.62 & 86.96 & 247.92 & 40.26 & 29.65 & 161.96 & 27.45 \\
75 & 84.63 & 87.72 & 247.69 & 43.32 & 31.90 & 165.06 & 30.99 \\
120 & 86.33 & 89.41 & 247.98 & 46.29 & 34.09 & 167.82 & 36.48 \\
\hline
\end{tabular}

Table 2. The characteristic value of DSC analysis of c-PET samples aged at $45^{\circ} \mathrm{C}$.

The results collected in Table 1 and 2 show that for the samples aged at $25^{\circ} \mathrm{C}$, the $\mathrm{T}_{\mathrm{g}}$ is within the range $73-74^{\circ} \mathrm{C}$; however, for the samples aged at $45^{\circ} \mathrm{C}$, the $\mathrm{T}_{\mathrm{g}}$ is in the range of $73-86^{\circ} \mathrm{C}$. As shown in Table 2, the values of $T_{g}$ and $T_{\max }$ of the samples aged at $45^{\circ} \mathrm{C}$, after 120 days aging, are about $18 \%$ and $15 \%$ higher than those of the unaged samples. Illers and Breuer (1963) indicated that the growth of spherulites is not completed when the amorphous part of C-PET is crystallized at relatively low temperatures for short periods. Spherulites grow from the existing nuclei and gradually fill the volume of the material [11]. In the present study, both position and intensity of the endothermic peak for samples aged at $45^{\circ} \mathrm{C}$ increase continuously with time. These results 
agree with the reports of Montserrat et al. for the cPET with a crystallinity degree of 0.32 [12]. The same results were also found in Atkinson's [13] and Karagiannidis's [14] researches. Enthalpic relaxation of the amorphous PET almost occurs at the temperatures close to the $T_{g}$ point. The results of this experiment showed that the aging of c-PET samples at $25^{\circ} \mathrm{C}$ does not have significant influence on the glass transition temperatures while at $45^{\circ} \mathrm{C}$ the aging of c-PET causes the $T_{g}$ point to increase (Figure 2). Ellis et al. observed formation of an aging peak following storage at 58 ${ }^{\circ} \mathrm{C}$ as detected by DSC [5]. The ascending trend of the $T_{g}$ point observed in Figure 2 for the samples aged closer to the glass transition point can be explained by relaxation process of the amorphous regions of the polymer due to mobility of the chain segments. It is clear that the extent of aging increases when increasing storage time; hence, the $\mathrm{T}_{\mathrm{g}}$ of $\mathrm{C}$-PET samples aged at $45^{\circ} \mathrm{C}$ after 40 and 120 days increase by $14 \%$ and $18 \%$ in comparison to the unaged sample.

\subsection{Effect of aging on the crystallization process}

The heating and cooling curves of c-PET samples aged at 25 and $45^{\circ} \mathrm{C}$ are shown in Figure 3 and 4 , respectively.
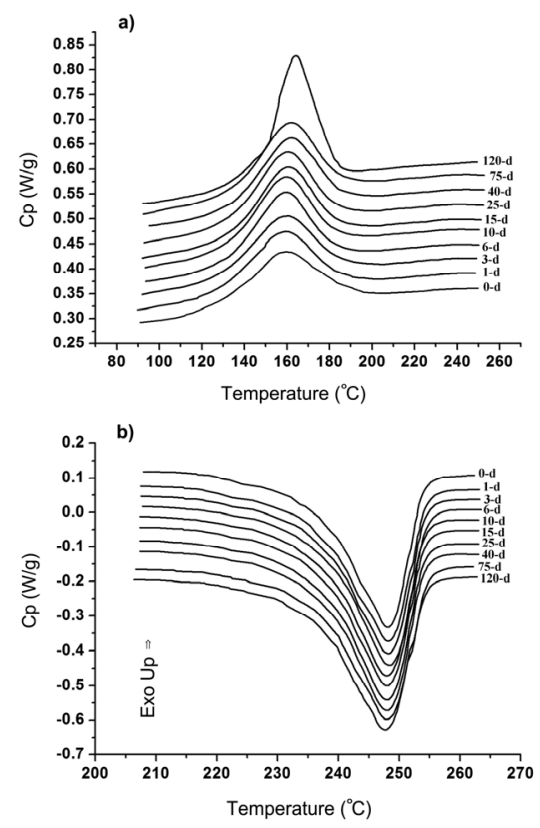

Figure 3. DSC curves of c-PET samples aged at $45^{\circ} \mathrm{C}$ :

(a) cooling process, (b) heating process.
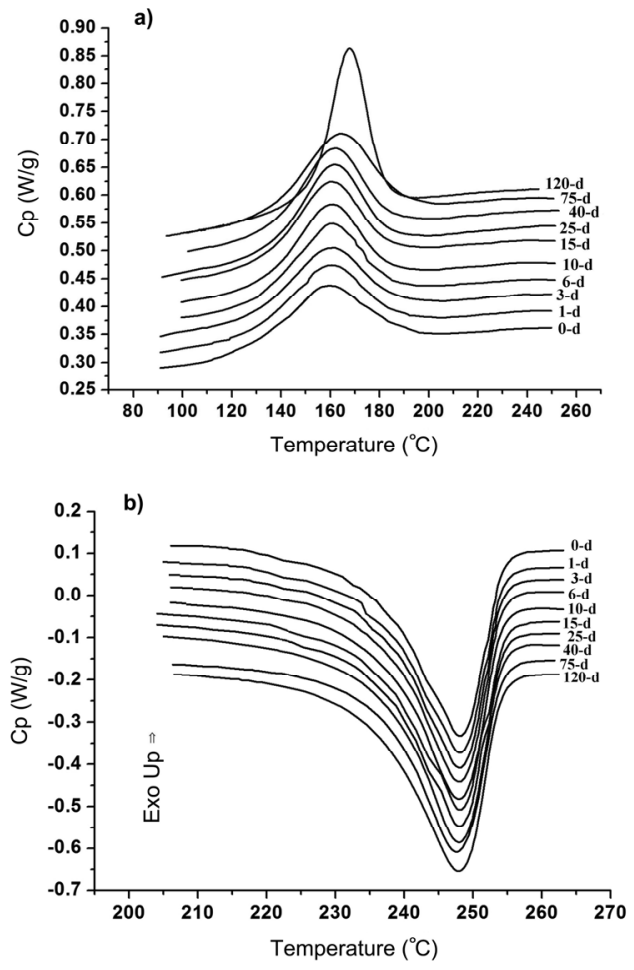

Figure 4. DSC curves of c-PET samples aged at $45^{\circ} \mathrm{C}$ : (a) cooling process, (b) heating process.

For samples aged at 25 and $45^{\circ} \mathrm{C}$, the crystallization temperature $\left(T_{c}\right)$ shifts to higher temperatures, but it is more considerable for samples aged at $45^{\circ} \mathrm{C}$ (See Tables 1 and 2). It means that the aging process enhances the crystallization process of polymer chains; thus, higher activation energy of the samples aged at closer temperature to the $T_{g}$ point results in a higher crystallization temperature. The enthalpic relaxation of polymer chains, especially at temperatures closer to the glass transition point, can provide a part of activation energy for segmental motion and rearrange polymer chains to form crystallites. Therefore, they begin to crystallize earlier or at higher temperatures from the melt point. As can be seen in Figures 3(b) and 4(b), the melt points of aged c-PET samples do not change considerably after aging.

Another characteristic of the melting process is the final degree of crystallinity shown in Tables 1 and 2 for different aged samples. The results show that the increase in $X_{c}$ for the samples aged at a 
temperature closer to the $\mathrm{T}_{\mathrm{g}}$ point is more considerable. The c-PET samples aged at $45^{\circ} \mathrm{C}$ showed about 13 and $21 \%$ increase in $X_{c}$ after 75 and 120 days aging times, respectively. Lu. et al. reported that the development of primary nuclei during storage of c-PET samples can enhance the final degree of crystallinity of the polymer [4]. Hence, higher degree of crystallinity of samples aged at $45^{\circ} \mathrm{C}$ in this study can be attributed to higher nuclei formation during storage and also to higher $\mathrm{T}_{\mathrm{c}}$ of these samples. The increase in crystallinity can limit the segmental chain motion, subsequently the amorphous phase is reduced because of the increase in the crystalline phase, thus the free volume of the polymer decreases and the $T_{g}$ point extends to a higher temperature [7].

\section{Conclusion}

Physical aging of the semicrystalline PET of $X_{c}=0.28$ at $45^{\circ} \mathrm{C}$ shows an endothermic peak shifted to higher temperatures with aging time, which is probably associated with the enthalpy relaxation of the amorphous region. The results show that at aging temperature of $25^{\circ} \mathrm{C}$ the relaxation process does not occur at the amorphous regions of PET. Probably, at lower aging temperatures, the chain segments of the amorphous region do not have enough mobility for the relaxation process. The samples aged at $45^{\circ} \mathrm{C}$ have higher activation energy for segmental arrangement of polymer chains in order for crystal formation to take place; therefore, they show higher degree of crystallinity. Finally, nuclei formation during storage can affect the overall crystallization process of the c-PET samples.

\section{References}

[1] Wunderlich B., Macromolecular Physics, Academic Press, New York, 1976, Vol. 2, Ch.7.

[2] Struik L. C. E., Physical aging in amorphous polymers and other materials, Elsevier Amsterdam, 1978.

[3] Struik, L. C. E., The mechanical behaviour and physical ageing of semicrystalline polymers: 2, Polymer, Vol. 28, No. 9, 1987, pp.1534-1542.

[4] Lu X. \& Hay J. N., The effect of physical aging on the rates of cold crystallization of poly(ethylene terephthalate), Polymer, Vol. 41, No. 20, 2000, pp. 7427-7436.
[5] Ellis A., Gordon D., King S. \& Jenkins, M., Physical ageing studies of poly(ethylene terephthalate) using SANS and DSC, Physica B: Condensed Matter, Vol. 385386, No. I, 2006, pp. 514-516.

[6] Doulache N., Khemici M. W., Gourari A. \& Bendaoud, M., DSC study of polyethylene terephtalate's physical ageing, Proceedings of the 2010 IEEE International Conference on Solid Dielectrics (ICSD 2010), art. no. 5568072

[7] Deng M., Allan J. M., Corbett J. T. \& Shalaby S. W., Effects of Thermal History and Physical Aging on Thermal Properties of Poly-L-Lactide, ASTM Special Technical Publication, Vol. 1396, 2000, pp. 58-68.

[8] Zhou H., Lofgren E. A. \& Jabarin, S. A. Effects of microcrystallinity and morphology on physical aging of poly (ethylene terephthalate), Journal of Applied Polymer Science, Vol. 106, No. 5, 2007, pp. 3435-3443.

[9] Zhou H., Lofgren E. A. \& Jabarin S. A., Effects of microcrystallinity and morphology on physical aging and its associated effects on tensile mechanical and environmental stress cracking properties of poly (ethylene terephthalate), Journal of Applied Polymer Science, Vol. 112, No. 5, 2009, pp. 2906-2917.

[10] Starkweather H. W., Zoller P. \& Jones G. A., Heat of Fusion of Poly(ethylene terephthalate), Journal of polymer science. Part A-2, Polymer physics, Vol. 21, No. 2, 1983, pp. 295-299.

[11] Illers K. H. \& Breuer, H., Molecular motions in polyethylene terephthalate, Journal of Colloid Science, Vol. 18, No. 1, 1963, pp. 1-31.

[12] Montserrat S. \& Cortes P., Physical ageing studies in semicrystalline poly (ethylene terephthalate), Journal of materials science, Vol. 30, No. 7, 1995, pp. 1790-1793

[13] Atkinson J., Hay J. \& Jenkins M., Enthalpic relaxation in semi-crystalline PEEK, Polymer, Vol. 43, No. 3, 2002, pp. 731-735.

[14] Karagiannidis P. G., Stergiou A. C. \& Karayannidis G. P., Study of crystallinity and thermomechanical analysis of annealed poly (ethylene terephthalate) films, European Polymer Journal, Vol. 44, No. 5, 2008, pp. 1475-1486. 